\title{
Effect of $C Y P 2 C 9$ gene polymorphisms on response to treatment with sulfonylureas in a cohort of Egyptian type 2 diabetes mellitus patients
}

\author{
Randa Fayez Abdel Salam • Reham Zeyada • \\ Noha Adel Osman
}

Received: 1 August 2012 / Accepted: 19 September 2012 /Published online: 29 September 2012

(C) Springer-Verlag London 2012

\begin{abstract}
Oral hypoglycemics are a widely prescribed group of drugs for the management of type 2 diabetes mellitus. Sulfonylureas (SUs) are the cornerstone of type 2 diabetes pharmacotherapy. The enzyme cytochrome P450 $2 \mathrm{C} 9$ (CYP2C9) is the main enzyme that catalyzes the biotransformation of SUs. It is encoded by the polymorphic gene $C Y P 2 C 9$ with two allelic variants namely $C Y P 2 C 9^{*} 2$ and $C Y P 2 C 9 * 3$ coding for variant allozymes with reportedly decreased metabolic capacity resulting in decreased SUs clearance and consequently prolonged and exacerbated action. The aim of this study was to investigate the influence of genetic polymorphisms of $C Y P 2 C 9$ on the response to glibenclamide, a second-generation sulfonylurea. Hundred type 2 diabetic patients were enrolled in the study. Genotyping was done on the LightCycler 2 by real-time polymerase chain reaction (PCR) hybridization probe assay. The results are the following: 53 patients were carriers of the wild genotype $\left(C Y P 2 C 9^{*} 1 * 1\right), 20$ were heterozygous for the variant $C Y P 2 C 9^{*} 2$ allele $\left(C Y P 2 C 9^{*} 1 * 2\right), 18$ were heterozygous for the variant $C Y P 2 C 9^{*} 3$ allele $\left(C Y P 2 C 9^{*} 1 / 3\right)$, and 9 were double heterozygous for both mutant alleles $\left(C Y P 2 C 9^{*} 2 * 3\right)$; of those double mutant genotype patients, two were also homozygous for the mutant $C Y P 2 C 9^{*} 2$ allele $(C Y P 2 C 9 * 2 * 2)$ and one patient was homozygous for the mutant $C Y P 2 C 9^{*} 3$ allele $\left(C Y P 2 C 9^{*} 3 * 3\right)$. Although there
\end{abstract}

R. F. A. Salam

Department of Internal Medicine,

Cairo University and Hospitals,

Cairo, Egypt

R. Zeyada $(\bowtie)$

Department of Clinical Chemistry, Cairo University and Hospitals,

Cairo, Egypt

e-mail: rzeyada@hotmail.com

N. A. Osman

Nephrology Department, Cairo University and Hospitals,

Cairo, Egypt was no significant difference in drug dosage between the four groups, there was however a significant association of the $C Y P 2 C 9^{*} 2 * 3$ genotype with better glycemic control. As conclusion, the better glycemic control observed can probably be attributed to slower metabolism of SUs by the carriers of the $C Y P 2 C 9^{*} 2 / 3$ genotype and consequently longer half-life or exacerbated effect of the SUs administered.

Keywords $C Y P 2 C 9 \cdot C Y P 2 C 9 * 2 \cdot C Y P 2 C 9 * 3 \cdot$ Type 2 diabetes $\cdot$ Sulfonylureas $\cdot$ Glibenclamide $\cdot$ Real-time PCR

\section{Introduction}

An estimated $9.1 \%$ of the populations from the Middle Eastern/North African region have type 2 diabetes $(32.8$ million) in 2011, and this is projected to reach 60 million in 2030. Ranking prevalence of type 2 diabetes all over the world, Egypt comes seventh with a comparative prevalence of $16.9 \%$ in the age group 20-79 years (IDF 2011).

Sulfonylureas (SUs) stimulate insulin release from pancreatic $\beta$-cells and have been the cornerstone of type 2 diabetes pharmacotherapy for over 50 years. Firstgeneration SUs were less potent and required higher doses to achieve efficacy and are no longer used. While secondgeneration group including glyburide (glibenclamide), glipizide, and glimepiride are now widely used and are much more potent compounds ( $\sim 100$-fold); they possess a more rapid onset of action and generally have shorter plasma halflives and longer duration of action compared to the firstgeneration agents (Evans and Rushakoff 2010).

Severe sulfonylurea-associated hypoglycemia is fatal in 1.4 $10 \%$ of cases and necessitates long and costly hospital stays (Holstein et al. 2005). Moreover, the risk of hypoglycemia may lead physicians to adjust blood glucose concentrations to above 
those identified as optimal for the prevention of microvascular, macrovascular, and neuropathic complications. Glibenclamide in particular has a greater tendency to cause hypoglycemic adverse effects than other sulfonylurea drugs (Nathan et al. 2009); thus, the identification and consideration of individual risk of hypoglycemia may be of great importance for the optimization of treatment.

When treating with SUs, one is bound to notice that there is considerable interindividual variability in pharmacokinetics, clinical efficacy, and adverse effects. Genetic factors are known to contribute to individual differences in bioavailability, drug transport, metabolism, and drug action. SUs are initiated at a low dose and titrated up to the optimal dose with intervals of 2-4 weeks until the glycemic target is achieved. Undertreatment will increase the risk of longterm complications, whereas overtreatment will lead to hypoglycemia (Kirchheiner et al. 2005).

Cytochrome P450 (CYP450) superfamily is a large and diverse group of enzymes. The function of most CYP enzymes is to catalyze the oxidation of organic substances. The substrates of CYP450 enzymes include metabolic intermediates such as lipids and steroid hormones, as well as drugs and other toxic chemicals. CYPs are the major enzymes involved in drug metabolism accounting for about $75 \%$ of the total number of different metabolic reactions (Guengerich 2008).

Humans have 57 genes and more than 59 pseudogenes divided among 18 families of CYP450 genes and 43 subfamilies (Nelson 2002). Cytochrome P450 2C9 (abbreviated CYP2C9) is an enzyme that in humans is encoded by the CYP2C9 gene located within a cluster of cytochrome P450 genes on chromosome 10q24 (Inoue et al. 1994). It is an important cytochrome $\mathrm{P} 450$ enzyme with a major role in the oxidation of both xenobiotic and endogenous compounds.

Human $C Y P 2 C 9$ has been shown to exhibit genetic polymorphism. In addition to the wild type $C Y P 2 C 9^{*} 1$, at least 32 single nucleotide polymorphisms have been reported within the coding region of the CYP2C9 gene producing the variant allozymes. CYP2C9*2 and CYP2C9*3 are among them. CYP 29C*2 reflects an Arg144Cys (R144C) (King et al. 2004) and CYP2C9*3 reflects an Ile359-Leu (I359L) change in the amino acid sequence and have reduced catalytic activity compared with the wild type (CYP2C9*1) (Sullivan-Klose et al. 1996).

The enzyme CYP2C9 plays an important role in the pharmacokinetics of SUs, where the second-generation sulfonylureas including glibenclamide are extensively metabolized in the liver, mainly by CYP2C9 and the two allelic variants, $\mathrm{CYP} 2 \mathrm{C} 9 * 2$ and $\mathrm{CYP} 2 \mathrm{C} 9 * 3$, were reported by several authors to result in decreased metabolic capacity (Miners and Birkitt 1998; Kirchheiner et al. 2005; Zhou 2009). This in turn can result in increased plasma drug concentration and enhanced activity of the drug, which can manifest either as greater therapeutic response or a higher incidence of hypoglycemic episodes. Studies among healthy volunteers have shown a significant influence of $C Y P 2 C 9$ polymorphisms on glibenclamide metabolism (Kirchheiner et al. 2002; Niemi et al. 2002; Yin et al. 2005). There have also been reports of higher risk of hypoglycemic episodes in poor metabolizers of glibenclamide among diabetic patients (Holestein et al. 2005).

Aim of our work was to investigate the prevalence of the $C Y P 2 C 9^{*} 2$ and $C Y P 2 C 9^{*} 3$ genotypes in a cohort of type 2 diabetes patients on the sulfonylurea glibenclamide and the effect of different genotypes on treatment outcome.

\section{Subjects and methods}

Study design and patients selection This study was conducted on a total number of 100 patients with type 2 diabetes in Kasr El Aini Diabetes Outpatient Clinic. Diabetes and diabetic complications were defined according to the American Diabetes Association criteria (2012). According to the Helsinki Declaration (World Medical Association 2008), the purpose of the study was explained to all the subjects included in the study and all participants gave their informed consent before joining the study and before physical examination and drawing of blood samples.

Inclusion criteria Type 2 diabetes patients on SUs oral hypoglycemic therapy.

Clinical examination Detailed diabetes and family history was accounted for; thorough medical examination was given to all participants including neurologic examination, blood pressure assessment, measurement of waist circumference, and calculation of body mass index.

Sampling After an overnight fast, $5 \mathrm{ml}$ blood sample was drawn from every patient. Two milliliters was collected on $\mathrm{Na}$ fluoride vacutainers for glucose assay and $3 \mathrm{ml}$ on EDTA vacutainer for genotyping. Samples were transferred to laboratory where plasma was separated for glucose assay while EDTA samples were stored frozen for 2 weeks until processed (DNA extraction and genotyping).

\section{Laboratory methods}

DNA extraction was done using the High Pure PCR Template Preparation Kit from Roche Diagnostics. Genotyping was done on Light Cycler 2 (Tortiello et al. 2006) using the LightMix human $C Y P 2 C 9^{*} 2$ and $C Y P 2 C 9^{*} 3$ kit (TIB MOLBIOL Syntheselabor GMBH, Eresburgstr 22-23 D12103 Berlin). 
Preparation of the reaction mix to the final volume of $20 \mu \mathrm{l}$ consisted of $1.2 \mu \mathrm{Mgg}^{+2}$ solution $25 \mathrm{mM}, 4 \mu \mathrm{l}$ reagent mix (primers and probes), $2 \mathrm{ml}$ Roche master, and $5 \mu \mathrm{l}$ of each sample that was completed to $20 \mu \mathrm{l}$ by adding $7.8 \mu \mathrm{l}$ water polymerase chain reaction (PCR)-grade.

The reaction consisted of amplification of a 374-bp fragment and a 180-bp fragment of the human CYP2C9 genome with specific primers. The $C Y P 2 C{ }^{*} 2$ was detected by the SimpleProbe probe (detected in channel 530) while human $C Y P 2 C 9^{*} 3$ with probe labeled with lightcycler Red 640 (detected in channel 640). The genotypes were identified by running a melting curve with specific melting points. For $C Y P 2 C 9^{*} 2$, the melting temperature $\left(T_{\mathrm{m}}\right)$ for the wild type was $58.5^{\circ} \mathrm{C}$ and for the mutant $50.5^{\circ} \mathrm{C}$, detected in channel 530. For $C Y P 2 C 9^{*} 3$, the $T_{\mathrm{m}}$ for the wild type was $48.3{ }^{\circ} \mathrm{C}$ and for the mutant $58.3{ }^{\circ} \mathrm{C}$, detected in channel 640 . The use of a color compensation file generated with the LightMixAssay color Compensation 530/640 was employed to identify the genotypes in the corresponding channel.

The programmed protocol consisted of the following steps: denaturation step with sample denaturation and enzyme activation at $95{ }^{\circ} \mathrm{C}$ for $10 \mathrm{~min}$; cycling of 45 cycles of PCR amplification of target DNA, at the following temperature profile, $95{ }^{\circ} \mathrm{C}$ for $5 \mathrm{~s}$ then at $60^{\circ} \mathrm{C}$ for $10 \mathrm{~s}$ then $72{ }^{\circ} \mathrm{C}$ for $15 \mathrm{~s}$; and finally melting curve analysis (Figs. 1, 2, and 3).

Glucose was assayed on automated analyzer Hitachi 917; commercial kits were supplied by (Roche Diagnostics, Germany) (Trinder 1969).

\section{Statistical methods}

The results were analyzed using the SPSS computer software package, version 15 (Chicago, IL, USA). Qualitative data were expressed as frequencies and percentages. For categorical data were assessed using chi-square test or Fischer exact test where appropriate. The quantitative data were expressed as median and range, and differences between the two groups were compared. KruskalWallis test with Mann-Whitney $U$ test for independent samples as post hoc multiple two-group comparisons was used. Logistic regression analysis was done to detect independent factors associated with blood sugar control. Differences were considered significant at $P \leq$ 0.05 (Knapp and Miller 1992).

\section{Results}

Of the 100 patients (19 males, 81 females), 94 were on concomitant treatment with two drugs, namely, glibenclamide and metformin, and six were on monotherapy with glibenclamide. There was no statistically significant difference in glibenclamide or metformin dose on comparing the various groups.

Table 1 shows genotype distribution among the hundred diabetic patients. The patients were divided into group 1, 53 patients carriers of the wild genotype designated $C Y P 2 C 9^{*} 1 / * 1$; group 2,20 patients heterozygous for the variant genotype $C Y P 2 C 9 * 2$ designated $C Y P 2 C 9 * 1 / 2$; group 3, 18 patients heterozygous carriers of the variant CYP $2 C 9^{*} 3$ genotype designated CYP $2 C 9^{*} 1 / 3$; and group 4 , nine patients heterozygous carriers of both variant genotypes $C Y P 2 C 9^{*} 2$ and $C Y P 2 C 9^{*} 3$ designated $C Y P 2 C 9^{*} 2 /$ *3. In group 4 , two patients were homozygous for the mutant $C Y P 2 C 9^{*} 2$ allele $\left(C Y P 2 C 9^{*} 2 * 2\right)$ as well as being heterozygous for the $C Y P 2 C 9^{*} 3$ and one patient was homozygous for the mutant $C Y P 2 C 9^{*} 3\left(C Y P 2 C 9^{*} 3 * 3\right)$ allele as well as being heterozygous for the $C Y P 2 C 9^{*} 2$ allele, all those three patients were included in this group for statistical purposes.

Table 2 shows the characteristics of the four studied groups regarding age, gender, family history, fasting plasma glucose, duration of diabetes, BMI, waist circumference, hypertension, and history of ischemic heart disease. There was no statistically significant difference between the four studied groups regarding all those parameters.

On examining the association between the glibenclamide dosage and various parameters namely BMI, waist circumference, metformin dosage, neuropathy and other comorbidities, and control of fasting blood sugar in different genotypes, the following was found: there was a significant association $(p=0.015)$ between genotype status of $C Y P 2 C 9$ and the control of diabetes where only group 4 (double
Fig. 1 Melting curve analysis for CYP2C9*2. Figure showing melting curves of three cases: 1 -wild genotype (CYP2C ${ }^{*} 1 /$

*1) with one peak at $T_{\mathrm{m}} 58.5^{\circ}$ C; 2 -heterozygous $\left(C Y P 2 C 9^{*} 1 / 2\right)$ showing two peaks at 50.5 and $58.5^{\circ} \mathrm{C} ; 3$ mutant $(C Y P 2 C 9 * 2 / * 2)$

showing one peak at $50.5^{\circ} \mathrm{C}$

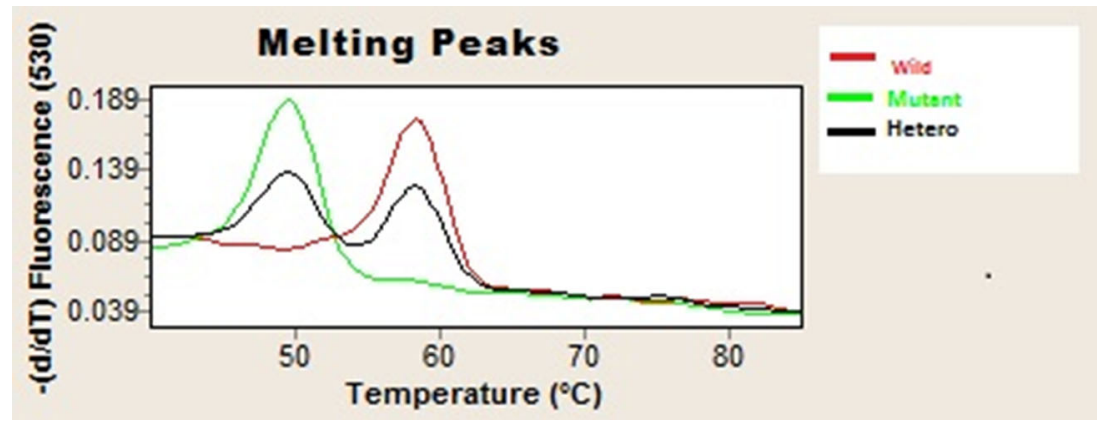






Fig. 2 Melting curve analysis for $C Y P 2 C 9^{*} 3$. Figure shows melting curves of two cases: $1-C Y P 2 C 9^{*} 3$ wild genotype $\left(C Y P 2 C 9^{*} 1 / * 1\right)$ showing one peak at $T_{\mathrm{m}} 48.3{ }^{\circ} \mathrm{C} ; 2$-heterozygous $\left(C Y P 2 C 9^{*} 1 / * 3\right)$ showing two peaks at $T_{\mathrm{m}} 48.3{ }^{\circ} \mathrm{C}$ and $58.3{ }^{\circ} \mathrm{C}$

heterozygous) was associated with better diabetes control (FBS <130) (Table 3). There was no association between different genotypes and the rest of the studied parameters. By logistic regression analysis, we did not find significant interaction of the age, gender, BMI, waist circumference, family history, and duration of the treatment or comorbidities with control of fasting blood sugar or treatment efficacy on comparing the four groups.

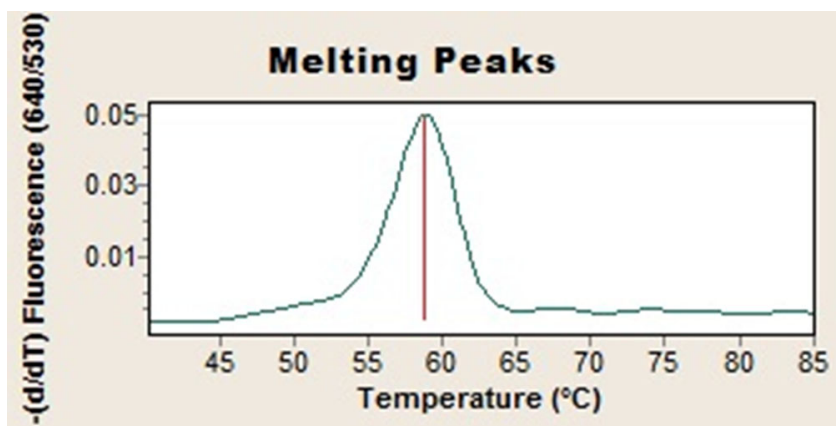

Fig. 3 Melting curve analysis for $C Y P 2 C 9^{*} 3$. Figure shows melting curves of a patient carrier of the mutant genotype $\left(C Y P 2 C 9^{*} 3 / * 3\right)$ with one peak at $T_{\mathrm{m}} 58.3{ }^{\circ} \mathrm{C}$
Table 1 Genotype distribution among diabetic patients

\begin{tabular}{ll}
\hline Genotype & Number of patients \\
\hline$C Y P 2 C 9 * 1 / 1$ & 53 \\
$C Y P 2 C 9 * 1 / 2$ & 20 \\
$C Y P 2 C 9 * 1 / 3$ & 18 \\
$C Y P 2 C 9 * 2 / 3^{\text {a }}$ & 9
\end{tabular}

${ }^{\text {a }}$ Two of the patients included in this group were also homozygous for the mutant $C Y P 2 C 9^{*} 2$ allele and one patient was also homozygous for the mutant $C Y P 2 C 9 * 3$ allele

\section{Discussion}

Comparing the prevalence of different $C Y P 2 C 9$ genotypes found in this study, we found $53 \%$ of the patients homozygous for the wild type allele (CYP2C9*1/*1), $20 \%$ heterozygous for the $C Y P 2 C 9 * 2$ allele, $18 \%$ heterozygous for the $C Y P 2 C 9 * 3$ allele, and only $9 \%$ double heterozygous $\left(C Y P 2 C 9^{*} 2 * 3\right)$ with two patients of this group also being homozygous for the mutant $C Y P 2 C 9 * 2$ allele and one homozygous for the mutant $C Y P 2 C 9^{*} 3$ allele.

Compared to the current study, the study by Holestein et al. (2005) revealed the following percentages in their three studied groups: a slightly higher prevalence of the wild genotype $C Y P 2 C{ }^{*} 1 / * 1(65,66.5$, and $65 \%$, respectively), frequency very close to ours of the $C Y P 2 C 9^{*} 1 / 2$ genotype $(20,18.4$, and $19.6 \%)$, lower frequency of $C Y P 2 C 9 * 1 / * 3$ genotype $(5,11.6$, and $11.5 \%)$, lower frequency of the $C Y P 2 C 9^{*} 2 / * 3(5,1.5$, and $1.7 \%)$, and frequency very close to ours of $C Y P 2 C{ }^{*} 2 / 22$ genotype $(0,1.5$, and $1.8 \%)$ and for $C Y P 2 C 9^{*} 3 * 3(5 \%, 0.6 \%$, and $0.4 \%)$.

Another study by Weise et al. (2010) that estimate the prevalence of CYP450 gene variations in 101 type 2 diabetes patients found the following: $C Y P 2 C{ }^{*} 2$ genotype $(20 \%), C Y P 2 C 9 * 3(22 \%)$, and in 102 nondiabetics CYP2C9*2 (24\%) and CYP2C9*3 (21\%). This study shows close resemblance to the frequencies observed in our study.

Metformin (a biguanide) has a glucoregulatory effect only in the presence of endogenous insulin by decreasing endogenous glucose production and reducing peripheral resistance to insulin (approximately 20-30\%) (Campbell 2009), and used concomitantly with SUs, they are the most commonly prescribed medications for management of type 2 diabetic patients in the Kasr El Aini Diabetes outpatient Clinic. Indeed 94 of our patients were on combined metformin and glibenclamide therapy and only six were on monotherapy with glibenclamide. Metformin is not metabolized. It is cleared from the body by tubular secretion and excreted unchanged in the urine (Robert et al. 2003).

In the current study, there was no statistically significant difference regarding glibenclamide dosage in carriers of 
Table 2 Demographic and patients characteristics

\begin{tabular}{lllll}
\hline Parameters & $\begin{array}{l}\text { Group 1 (CYP2C9*1*1) } \\
(n=53)\end{array}$ & $\begin{array}{l}\text { Group 2 }(C Y P 2 C 9 * 1 / 2) \\
(n=20)\end{array}$ & $\begin{array}{l}\text { Group 3 }(C Y P 2 C 9 * 1 / * 3) \\
(n=18)\end{array}$ & $\begin{array}{l}\text { Group } 4(C Y P 2 C 9 * 2 / 3) \\
(n=9)\end{array}$ \\
\hline Age (years) & $54(34-76)$ & $50(32-65)$ & $55(38-70)$ & $55(43-72)$ \\
Gender, M/F & $9 / 44$ & $1 / 19$ & $7 / 11$ & $2 / 7$ \\
BMI $\left(\mathrm{kg} / \mathrm{m}^{2}\right)$ & $32(22-44)$ & $32(21-48)$ & $31(25-45)$ & $36(26-39)$ \\
Waist $(\mathrm{cm})$ & $96(78-139)$ & $109(70-120)$ & $93(73-137)$ & $97(73-120)$ \\
Family history & $34(64 \%)$ & $8(42 \%)$ & $8(47 \%)$ & $4(44 \%)$ \\
Duration (years) & $5(1-22)$ & $6(1-15)$ & $4(1-15)$ & $130(99-280)$ \\
FPG (mg/dl) & $170(80-290)$ & $150(80-280)$ & $130(75-300)$ & $1(11 \%)$ \\
Comorbidities & & $8(40 \%)$ & $6(33 \%)$ & 0 \\
Neuropathy & $18(34 \%)$ & 0 & $1(5.6 \%)$ & $2(22 \%)$ \\
IHD & $1(1.9 \%)$ & $9(45 \%)$ & $6(33 \%)$ & 0 \\
HTN & $15(28 \%)$ & $1(5 \%)$ & 0 & $9(100 \%)$ \\
Stroke & 0 & $19(95 \%)$ & $17(94 \%)$ & \\
Double therapy & $49(92 \%)$ & & \\
\hline
\end{tabular}

Data are median (and range), number (frequency), or ratio of patients

$M$ male, $F$ female, IHD ischemic heart disease, HTN hypertensive, BMI body mass index, FPG fasting plasma glucose

different genotypes, as well as no association of the dosage with genotype or metformin dosage or the other studied parameters. There was however an important observation, a significant association of the genotype with the diabetes control status taking the cutoff for controlled fasting plasma glucose of $130 \mathrm{mg} / \mathrm{dl}$ as recommended by the ADA (2011), where a better diabetes control was observed in carriers of the $C Y P 2 C 9^{*} 2 * 3$ genotype. And since there was no significant difference in the metformin or glibenclamide dosage between the different studied groups, and since metformin is not metabolized by CYP450, we assume that the better control can be attributed to the different rate of metabolism of SUs administered, namely the slower metabolism by the carriers of the double heterozygous genotype (CYP2C $9 * 2$ / *3). As early as 1998, Miners and Birkett observed that the genotypes $C Y P 2 C 9 * 2 / * 3$ and $C Y P 2 C 9 * 3 / * 3$ account for the slow metabolizer phenotype of many CYP2C 9 substrates.

In the work by Kirchheiner in 2002, on healthy subjects, pharmacokinetics of glibenclamide depended significantly on CYP2C9 genotypes where in homozygous carriers of genotype $C Y P 2 C 9^{*} 3 * 3$, total oral clearance was less than half that of the wild type genotype $C Y P 2 C 9^{*} 1 / * 1$. The study done by Niemi et al. (2002) on 29 healthy volunteers revealed that the $C Y P 2 C 9^{*} 2 / 33$ genotype was associated with significantly lower clearance of SUs while the heterozygous genotypes with one wild type allele $\left(C Y P 2 C 9^{*} 1 / * 3\right.$ and CYP2C $9 * 1 * 2$ ) showed only a slight decrease in the oral clearances of glibenclamide.

Later work by Holestein et al. (2005) showed that sulfonylurea-treated patients who possessed the $C Y P 2 C 9 * 3 /$ $* 3$ or $C Y P 2 C 9 * 2 / 3$ genotype had 5.2-times the odds of a severe hypoglycemic events than the other $C Y P 2 C 9$ genotype groups and came to the conclusion that, although not the most prominent risk factor, $C Y P 2 C 9$ genotypes predictive of low enzyme activity $(C Y P 2 C 9 * 3 * 3$ and $C Y P 2 C 9 * 2 * 3)$ should be considered as one but not the main risk factor for severe hypoglycemia resulting from treatment with sulfonylurea oral hypoglycemic agents.

Surendiran et al. (2011) came to the conclusion that genetic polymorphisms of CYP2C9 have a significant effect on the response to therapy with glibenclamide among 80 type 2 diabetes mellitus patients. In that study, the variant $C Y P 2 C 9^{*} 1 * 3$ and $C Y P 2 C 9^{*} 1 * 2$ genotypes were associated with controlled diabetic status, while the wild genotype of $C Y P 2 C 9^{*} 1 / * 1$ was associated with uncontrolled diabetic status; the cutoff for fasting blood sugar was $110 \mathrm{mg} / \mathrm{dl}$.

Table 3 Association of glucose control with different genotypes

\begin{tabular}{lllll}
\hline Parameters & $\begin{array}{l}\text { Group 1 } \\
(n=53)\end{array}$ & $\begin{array}{l}\text { Group 2 } \\
(n=20)\end{array}$ & $\begin{array}{l}\left.\text { Group 3 }\left(C Y P 2 C 9^{*} 1 / * 2 C\right)^{*} 1 / * 3\right) \\
(n=18)\end{array}$ & $\begin{array}{l}\text { Group 4 }(C Y P 2 C 9 * 2 / * 3) \\
(n=9)\end{array}$ \\
\hline FBS controlled & $21(41.2 \%)$ & $8(42 \%)$ & $12(70 \%)$ & $8(89 \%) *$ \\
\hline
\end{tabular}

Data are presented as number (percentage)

${ }^{*} p<0.05$, significance 
On the other hand, the work done by Swen et al. (2010) to investigate the effect of CYP2C9 polymorphisms on prescribed dose and time-to-stable dose of sulfonylureas in primary care patients with type 2 diabetes mellitus came to the conclusion that no significant effects of the CYP2C $9 * 2$ and $C Y P 2 C 9^{*} 3$ alleles were found. However, a trend towards a lower stable SUs dose for carriers of the $C Y P 2 C 9^{*} 3$ allele was observed and it was their conclusion that genotyping for the $C Y P 2 C 9^{*} 2$ and $C Y P 2 C 9^{*} 3$ alleles currently appears to have no clinical implications for dosing of SUs in primary care patients with type 2 diabetes mellitus.

In conclusion, in the current study, since the glibenclamide drug dosage did not differ significantly among different genotypes, the association of $C Y P 2 C 9 * 2 / 3$ genotype with better diabetes control can probably be attributed to slower metabolism and consequently longer half-life. The field of pharmacogenomics of oral antidiabetic medications has taken some big steps in recent years. Diabetes being the new world pandemic with its high prevalence and the ever expanding population of type 2 diabetes patients is entitled to an ongoing in-depth look into pharmacogenomics of various drugs used for its management, bearing in mind that better control means less short- and long-term complications and far less economic burden.

\section{References}

American Diabetes Association (2011) Standards of Medical Care in Diabetes-2011. Diabetes Care 34:S11-S61. doi:10.2337/dc11S011

American Diabetes Association (2012) Diagnosis and classification of diabetes mellitus. Diabetes Care 35(Suppl 1):S64-S71

Campbell RK (2009) Type 2 diabetes: where we are today: an overview of disease burden, current treatments, and treatment strategies. J Am Pharm Assoc 49(Suppl 1):S3-S9. doi:10.1331/ JAPhA.2009.09077

Evans JL and Rushakoff RJ. Oral pharmacological agents for type 2 diabetes (2010): oral agents, incretions and other "non-insulin" pharmacologic interventions for diabetes, Endo Text. Org.-The Endocrine Source, Diabetes Manager (Eds. I. D. Goldfine and R. J. Rushakoff) last author version May 2010; Available at http:// diabetesmanager.pbworks.com/w/page/17680289/Oral-Pharmaco logical-Agents-for-Type-2-Diabetes. Accessed 31 July 2012

Guengerich FP (2008) Cytochrome p450 and chemical toxicology. Chem Res Toxicol 21(1):70-83

Holstein A, Plaschke A, Ptak M, Egberts EH, El-Din J, Brockmöller J, Kirchheiner J (2005) Association between CYP2C9 slow metabolizer genotypes and severe hypoglycaemia on medication with sulphonylurea hypoglycaemic agents. Br J Clin Pharmacol 60:103-106

Inoue $\mathrm{K}$, Inazawa J, Suzuki Y, Shimada T, Yamazaki H, Guengerich PF, Abe T (1994) Fluorescencein situ hybridization analysis of chromosomal localization of three human cytochrome P450 2C genes (CYP2C8, 2C9, and 2C10) at 10q24.1. Jpn J Hum Genet 39 (3):337-343

International Diabetes Federation. IDF (2011) Diabetes Atlas, 5th edn. International Diabetes Federation, Brussels. Available at: http:// www.idf.org/diabetesatlas
King BP, Khan TI, Aithal GP, Kamali F, Daly AK (2004) Upstream and coding region $\mathrm{CYP} 2 \mathrm{C} 9$ polymorphisms: correlation with warfarin dose and metabolism. Pharmacogenetics 14(12):813822

Kirchheiner J, Brockmoller J, Meineke I, Bauer S, Rohde W, Meisel C et al (2002) Impact of CYP2C9 amino acid polymorphisms on glyburide kinetics and on the insulin and glucose response in healthy volunteers. Clin Pharmacol Ther 71:286-296

Kirchheiner J, Roots I, Rosenkranz B, Goldammer M, Brockmoller J (2005) Effect of genetic polymorphisms in cytochrome p450 (CYP) 2C9 andCYP2C8 on the pharmacokinetics of oral antidiabetic drugs: clinical relevance. Clin Pharmacokinet 44:1209-1225

Knapp RG, Miller MC (1992) Describing the performance of a diagnostic test. In: Knapp RG, Miller MC (eds) Clinical epidemiology and biostatistics, 1 st edn. Williams \& Wilkins, Baltimore, pp 41-42

Miners JO, Birkett DJ (1998) Cytochrome P4502C9: an enzyme of major importance in human drug metabolism. Br J Clin Pharmacol 45:525-538

Nathan DM, Buse JB, Davidson MB, Ferrannini E, Holman RR, Sherwin R et al (2009) Medical management of hyperglycaemia in type 2 diabetes mellitus: a consensus algorithm for the initiation and adjustment of therapy: a consensus statement from the American Diabetes Association and the European Association for the Study of Diabetes. Diabetologia 52:17-30

Nelson DR (2002) Mining databases for cytochrome P450 genes. Methods Enzymol 357:3-15

Niemi M, Cascorbi I, Timm R, Kroemer HK, Neuvonen PJ, Kivisto KT (2002) Glyburide and glimepiride pharmacokinetics in subjects with different CYP2C9 genotypes. Clin Pharmacol Ther $72: 326-332$

Robert F, Fendri S, Hary L, Lacroix C, Andréjak M, Lalau JD (2003) Kinetics of plasma and erythrocyte metformin after acute administration in healthy subjects. Diabetes Metab 29(3):279-283

Sullivan-Klose TH, Ghanayem BI, Bell DA, Zhang ZY, Kaminsky LS, Shenfield GM, Miners JO, Birkett DJ, Goldstein JA (1996) The role of the CYP2C9-Leu359 allelic variant in the tolbutamide polymorphism. Pharmacogenetics 6(4):341-349

Surendiran A, Pradhan SC, Agrawal A, Subrahmanyam DKS, Rajan S, Anichavezhi D, Adithan C (2011) Influence of CYP2C9 gene polymorphisms on response to glibenclamide in type 2 diabetes mellitus patients. Eur J Clin Pharmacol 67:797-801

Swen JJ, Wessels JA, Krabben A, Assendelft WJ, Guchelaar HJ (2010) Effect of CYP2C9 polymorphisms on prescribed dose and timeto-stable dose of sulfonylureas in primary care patients with type 2 diabetes mellitus. Pharmacogenomics 11(11):1517-1523

Toriello M, Meccariello P, Mazzaccara C, Di Fiore R, Esposito C, Sacchetti L (2006) Comparison of the TaqMan and LightCycler systems in pharmacogenetic testing: evaluation of CYP2C $9 * 2 / * 3$ polymorphisms. Clin Chem Lab Med 44(3):285-287

Trinder P (1969) Determination of blood glucose using an oxidaseperoxidase system with a non-carcinogenic chromogen. J Clin Path 22(2):158-161

Weise A, Prause S, Eidens M, Weber MM, Kann PH, Forst T, Pfützner A (2010) Prevalence of CYP450 gene variations in patients with type 2 diabetes. Clin Lab 56(7-8):311-318

World Medical Association (2008) Declaration of Helsinki. Ethical principles for medical research involving human subjects, the 59th WMA General Assembly, Seoul, South Korea

Yin O, Tomlinson B, Chow S (2005) CYP2C9, but not CYP2C19, polymorphisms affect the pharmacokinetics and pharmacodynamics of glyburide in Chinese subjects. Clin Pharmacol Ther 78:370-377

Zhou K, Donnelly L, Burch L et al (2009) Loss-of function CYP2C9 variants improve therapeutic response to sulfonylureas in type 2 diabetes (2009): a Go-DARTS Study. Clin Pharmacol Ther 87 (1):52-56 